\title{
Intuitions, principles and consequences
}

A B Shaw Retired Consultant Physician, Harewood, Leeds

\begin{abstract}
Some approaches to the assessment of moral intuitions are discussed. The controlled ethical trial isolates a moral issue from confounding factors and thereby clarifies what a person's intuition actually is. Casuistic reasoning from situations, where intuitions are clear, suggests or modifies principles, which can then help to make decisions in situations where intuitions are unclear. When intuitions are defended by a supporting principle, that principle can be tested by finding extreme cases, in which it is counterintuitive to follow the principle. An approach to the resolution of conflict between valid moral principles, specifically the utilitarian and justice principles, is considered. It is argued that even those who justify intuitions by a priori principles are often obliged to modify or support their principles by resort to the consideration of consequences.

(Fournal of Medical Ethics 2001;27:16-19)
\end{abstract}

Keywords: Intuitions; principles; consequences; utilitarianism

A moral intuition is an immediate apprehension of the mind, without reasoning, about what it is right to do in a particular situation. However, those who wish to convince others of the rightness of their intuitions must offer reasons. They can point to a moral principle underlying the intuition (deontologists) or to the likely results of the inspired action (consequentialists).

Utilitarianism, the commonest form of consequentialism, gives priority to one principle, the maximisation of general wellbeing. Utilitarians start from the same premise and speak the same moral language. Disputes between them are potentially soluble by gathering evidence about consequences.

When intuitions are supported by other principles, disputes about them may be insoluble. Different people assign different priorities to each principle. There may also be disagreement about the scope of a principle, whether or not it applies in a particular case.

This paper is devoted to the consideration of the limited number of ways in which moral intuitions, underlying principles, and the scope of their application can be rationally considered. It will be suggested that even deontologists are obliged to take account of predicted consequences.

\section{The controlled ethical trial}

The first method discussed is simply a way a person can clarify his or her own intuition in a complex situation and thereby avoid counterintuitive action.

Kuhse and Singer suggested that the technique of the randomised controlled trial could be applied to ethical problems. ${ }^{2}$ In these trials typically two groups of patients are matched with regard to all factors which might affect the response to a treatment and then one is given the test treatment and the other the control treatment. By this means the real effect of the test treatment can be determined. A similar technique allows a moral issue to be isolated from confounding considerations.

\section{The clarification of intention}

Only action which is intended, can be said to proceed from an intuition. Thus Warnock points out that when a doctor relieves distress with opiates in a dose likely to hasten death, it may be unclear whether death is intended as well as analgaesia. ${ }^{3} \mathrm{It}$ may be unclear to the doctor as well as the onlooker. If death is only foreseen but not intended, a side effect not a goal of treatment, then morally and legally the management is justified by the double effect doctrine but not if death is actually intended.

The doctor can clarify her intention by asking two questions, which will isolate the two effects from each other. Would the opiates be used if they would relieve distress but not shorten life? Would alternative treatment be used, if it relieved distress equally well but did not shorten life? Similarly, this factor isolation technique can be used to determine whether the doctor's intention is to cause death or to stop useless treatment when nutrition and hydration are withdrawn from persistent vegetative state (PVS) patients. Would it be done if death did not result?

\section{Intuition about ageism}

There is much disagreement about the relevance of chronological age to the fairness of rationing decisions in medicine. Some believe that younger patients should take priority over older patients when life-prolonging treatment has to be rationed. Many disagree. The ethical trial can be used to determine our personal intuition about this in principle, in advance of the detailed argument.

If two patients had the same urgent need of a single available donor heart and there was nothing to choose between them, except that one was aged 
30 years and the other aged 60 years, who should get the heart and live? There is rarely just one difference between patients but for the exercise we will assume that only chronological age differentiates them and that their chronological ages reflect their biological ages.

If you believe that a coin should be spun to decide, then your intuition is that age should play no part in rationing decisions, which concern the prolongation of life. If it is thought that the heart should go to the younger patient-or perhaps the older one- then the intuition is that marked differences in age ought to be relevant to such rationing decisions.

In the clinical trial observer bias must be eliminated and in the ethical trial influences on the agent unrelated to ethics must be excluded. A young person might be ageist out of self interest or lack of empathy with the old. ${ }^{4}$ However, a young person who would spin a coin, rather than give preference to the young, would presumably do so for moral reasons. Similarly an older person who would give the heart to the younger patient would also be morally motivated.

\section{The casuistic method}

This technique is helpful when there is no clear intuition about what is right in a situation and to ensure that intuitions in different situations are morally consistent.

It is analogous to the methods of case law. There the judgment made in a previous similar case is applied to the current problem. More usefully, the principle underlying the judgment in the first case is applied to the second. When faced with a moral dilemma we look for a morally similar situation in which our intuition about right or wrong is clearer and apply the principle underlying that intuition.

\section{Deception}

A psychotic man who refused medication was given it surreptitiously in his tea. The nurse who did this at the request of the doctor was suspended. Deception had been used to obtain consent to beneficial treatment. Leaving aside the harsh punishment of someone who meant well, conferred benefit and acted on advice it was reasonable to trust, is it ever right actively to deceive a patient in his own interest?

If a schizophrenic was about to jump off a ledge because a voice over the radio had told him to do so, would you tell him an announcement revoking the order had just been made? If he refused all injections which had not received a papal blessing, would you tell him they had? Do you tell the child that the medicine is lovely and you wish you could have it? Let us assume that deception seems right in these cases.

What is the underlying moral principle? It seems that people may be deceived into accepting a benefit if they cannot distinguish between fact and fantasy or if they cannot process facts in a rational way. Their autonomy is neither reduced by decep- tion nor increased by truth. Therefore the scope of the principle that doctors must not obtain consent to treatment by deception is limited in an emergency to rational agents. On the other hand those whose intuition is against deception in the comparator cases, will be fortified in their opposition to deception in the test case and will maintain the undiluted principle.

Those who accept that the principle of respect for the autonomy of patients does not invariably exclude deception can still oppose it on utilitarian grounds. There might be sound reasons to believe it would be counterproductive overall, if health service professionals were known to resort to the deception, even of incompetent patients, to obtain acquiescence to treatment.

\section{The extreme case test}

Harris points out that the principles used to justify firmly held intuitions can be tested by looking for situations in which it is counterintuitive to follow the principle. ${ }^{6}$

We owe to Popper the concept that a scientific law is characterised by its falsifiability. ${ }^{7}$ An inconsistent observation falsifies it but any number of consistent observations do not definitively establish it as true. Moral principles underlying intuitions can be examined by looking for extreme situations, which will test the principle.

A scientific law is falsified by an inconsistent objective observation and it is argued that a moral law can be falsified by an inconsistent subjective intuition. Although this seems less compelling, it really is not. A scientific law is a description of the way things happen and is falsified when they do not happen that way. A moral principle is a description of the way we feel we should act and is falsified by a situation in which we feel we should act otherwise.

The scientific community does not modify a scientific law until a contrary observation has been widely confirmed. Similarly, the moral community does not modify a moral principle, unless intuitions which are inconsistent with it, are generally felt.

\section{Euthanasia}

Let us take the principle that it is not permissible actively to kill an innocent person for any reason, even at that person's understandable request. Those who follow that principle regard euthanasia as immoral. A test case is offered.

In the film made from the book, The Last of the Mohicans, the hero, fleeing from the Indian camp, shoots the British officer hung screaming over the fire. He does not consult the poor man but reasonably assumes he would prefer a quick death from a bullet to a slow and agonising death in the flames.

Obviously this is an extreme and unusual situation not typically met in National Health Service (NHS) practice. Once it is accepted, however, that the action was right-and it is difficult to see how any reasonable person would not do so-it is no longer possible to maintain that it is always wrong to kill an innocent person. There is in fact 
relevance to medical practice because some kinds of distress, not always pain, are difficult to overcome. Shortness of breath or a sense of shame at dependency are examples.

The technique discovers moral inconsistency. It is illogical to regard the sanctity of life as an inviolable principle and also agree with the shooting of the officer. It is illogical to agree with the shooting and regard euthanasia as inherently wrong in principle. As with the deception of the incompetent, those whose intuition is against the legalisation of euthanasia can still support their opposition with good utilitarian reasons.

\section{Ageism}

The personal intuition about ageism in rationing has been clarified but principles supporting the clarified intuition must be tested. One argument against ageism is that distributive justice dictates that everyone should have what is best for him or her, however little that best may be. So it is irrelevant that a young person whose life is saved is likely in general to live longer than is an old person given the same treatment. That moral principle is opposed by the utilitarian principle that doctors should use limited resources to achieve maximum benefit. How can a conflict between valid but mutually inconsistent or even incommensurable principles be resolved?

Savulescu tackles the problem by suggesting a hybrid of the utilitarian and the justice principles. $\mathrm{He}$ advocates the distribution of medical benefit by using a plateau not a scalar relation between the amount of potential benefit and the action indicated. Thus, a prolongation of life by perhaps a year, not less, should give a patient a claim to treatment equal to that of someone who might live many years with the treatment,

The rationale of this approach is that both principles give counterintuitive answers in the extreme situation. Most utilitarians would concede that if the extra prolongation of life for the young was measured in weeks, justice should take priority. Those who would usually give priority to justice would probably admit that a prolongation of one life by ten years is more important than a prolongation of two or even more lives by one day.

It is clear that an arbitrary point has to be chosen as to when the principle of justice should yield priority to the utilitarian principle and it is inevitable that we would all choose different points. Two people choosing widely different points could still map out an area of agreement. They could both agree that the other was motivated by a valid moral principle. They could both agree that the other's choice, though wrong, was reasonable and not extreme. They could both agree to examine the consequences of the view which prevailed.

\section{Determining the scope of a principle}

A principle cannot be used to support an intuition if its scope does not extend far enough to do so. Its scope must be determined rationally.
Most will accept Kant's categorical imperative that rational beings must not be used purely as a means but are ends in themselves. ${ }^{9}$ We extend the scope of its application to humans, who are not rational and to persons now dead. To what extremes should it be taken?

Few would use organs, useless to a patient who has just died, against the known wishes of that patient, even to save the life of another patient. However, the ancient Egyptians would have been aghast at the indignities to which we submit their mummified bodies, just to satisfy our curiosity. I doubt that we are following a principle that respect for people's autonomy reduces in proportion to the time during which they have been dead. We know that nobody alive will be frightened or offended by what is done to Egyptian mummies. We do not respect the autonomy of dead persons when failing to do so does not have undesirable consequences.

Consider experiments on embryos for the benefit of society in the future, leaving aside abortion, which benefits a known individual now. We permit experiments on an embryo in a dish, provided it has no chance of implantation. We would not permit them on an embryo in the uterus of a woman who has decided on abortion. Is there a moral distinction between the embryos, which would support this demarcation of the Kantian principle? A woman might change her mind about abortion and then harm would have been done to a future person. The death of the embryo in the dish is more certain and it cannot be effectively further harmed. Also the embryo in the dish dies as soon as medical intervention stops. The embryo in the uterus will develop unless it is deliberately killed. The limitation of the principle is rational.

There is more reluctance to countenance engendering embryos specifically for exploitation. To create an embryo with a chance of life and then use it, when its chance has gone, tests the Kantian principle. To create one solely for exploitation is a more fundamental assault on it.

\section{The failed test}

Different approaches can be adopted when a seemingly sound moral principle clashes with a clear intuition. It is possible simply to act counterintuitively, although this would be neither intellectually nor emotionally satisfying, because the intuition which tests the principle is usually based on another valid moral principle, such as the duty to relieve distress.

Beauchamp and Childress suggest that moral principles are inductively derived from moral intuitions about situations and then deductively applied to new situations. ${ }^{10}$ Independent intuitions about new situations also modify previously derived principles, producing a coherent but changing moral equilibrium.

A common response is in fact to modify an accepted principle when it suggests counterintuitive action. Modification of the principle rejecting the exploitation of humans can permit embryo 
experimentation. Modifying the sanctity of life principle can permit euthanasia.

It is suggested that consideration of consequences is unavoidable when intuitions and principles clash.

\section{Consequential considerations}

The case of the man burning in the fire suggests that an intuition is more often an immediate appreciation and valuation of consequences than a swift application of accepted moral principle.

Absolutist deontologists would refuse to allow their principles to be overridden by consequentialist considerations, no matter how much harm or benefit resulted from following a principle. They might indeed prefer to be unaware of consequences, in case the sight of misery caused human weakness to overwhelm the dictates of principle. Many deontologists however, would accept the moral importance of consequences, which often derives from the principle of beneficence. The absolutist approach is untenable.

Few would claim that the wellbeing of others was unimportant to them. It is illogical to treat what is important as irrelevant to decisions which affect it.

Those who consider it their duty to promote morality, not happiness, must also consider consequences. Fertility control is an example. Most would consider abortion more immoral than contraception, late abortion worse than early abortion, and infanticide worse than abortion. It also seems probable that when doctors or legislators prevent or delay contraception some women wil resort to abortion, and so on. If one person can foresee that pressure on another person to avoid an immoral act, might cause that other person to perform an even more immoral act, then both persons are responsible for the greater evil. If you know that your action is partly causal of an effect, even if not sufficient to cause that effect, you are a joint agent in producing the effect. And if the doctor or legislator claims that sticking to principles, despite the few unfortunate events, has reduced the total of immorality, that too is a consequential argument.

Principles are generally incommensurable but the utilitarian principle lends itself most easily to quantitation, by the measurement of consequences, in terms not just of numbers of people affected but also in terms of size of benefit. The QALY( Quality Adjusted Life Years) system and the quantitation of the sacrifice which a patient would make to achieve a particular benefit, are attempts to compare benefits which seem incommensurable, such as prolongation of life and relief of distress.

In summary, most deontologists inevitably take consequences into consideration. It would be difficult to discuss moral problems rationally with an absolutist who disregarded consequences and gave absolute priority to one principle over all others.

\section{Conclusion}

Some methods of determining and assessing intuitions have been considered. One clarifies what our intuition is. One tests the principle on which it is based. Another seeks to solve doubt in a test case by finding comparator cases and deriving or modifying an appropriate principle from them. A fourth tries to resolve the conflict between utilitarian and other principles by a semiquantitative approach

These methods detect inconsistency but do not demonstrate the rightness of an intuition. They might therefore permit systematic moral error. Many would accept, however, that moral intuitions often are right or at least consistent with a widespread view of what is right. Logical analysis of intuitions is therefore more likely to promote a morality which is consistently right, rather than one which is consistently wrong.

It has also been suggested that consideration of the consequences of an intuition is unavoidable even for those whose intuitions are supported by $a$ priori moral principles. Because consequences are uncertain, consequentialists, especially utilitarians, know that they may regret doing what appeared right at the time and are obliged to check after the event that their decision was right, in a way that deontologists do not. When reasonable people hold firm but opposing intuitions there is something to be said for uncertainty before the decision and review after it.

A B Shaw MD, FRCP, is a retired Consultant Physician.

\section{References}

1 Gillon R. Medical ethics: four principles plus attention to scope. Fournal of the American Society of Law, Medicine and Ethscope. Fournal of the Am

2 Kuhse H, Singer P. Introduction: the nature of ethical argument. In: Singer P, Kuhse $\mathrm{H}$, Buckle S, Dawson $\mathrm{K}$, Kasimba P, eds. Embryo experimentation. Cambridge: Cambridge University Press, 1990: 37-42.

3 Warnock M. An intelligent person's guide to ethics. London: Duckworth, 1998

4 Grimley Evans J. Health care rationing and elderly people. In: Tunbridge M, ed. Rationing of health care in medicine. London: Royal College of Physicians of London, 1993: 43-52.

5 Kellett JM. Suspension of nurse who gave drug on consultant's instruction. British Medical fournal 1997;314:1043.

6 Harris J. The value of life. London: Routledge, 1985: 235-7.

7 Magee B. Popper. London: Fontana/Collins, 1973: 22-3.

8 Savulescu J. Consequentialism, reason, value and justice. Bioethics 1998;12:212-35.

9 Kant I. The moral law [translated by Paton HJ]. London: Hutchinson's University Library, 1947: 100-2.

10 Beauchamp TL, Childress JF. Principles of biomedical ethics [4th ed]. Oxford: Oxford University press, 1994:14-26. 